\title{
UTILIZAÇÃO DE UM PROGRAMA DE ANÁLISE ESTRUTURAL COMO ESTRATÉGIA DE ENSINO A DISTÂNCIA NA ENGENHARIA: UM ESTUDO SOBRE CARGAS DE VENTO GERADAS PELA SIMULAÇÃO AUTOMÁTICA
}

\author{
Joice Alves da Costa - costa-joyce-alves@hotmail.com \\ Universidade Federal Rural do Semi-Árido \\ $R N-233$ \\ 59780-000 - Caraúbas - Rio Grande do Norte \\ Ingrid Rebouças de Moura - ingridmoura@ufrn.edu \\ Universidade Federal do Rio Grande do Norte \\ Capim Macio \\ 59077-080 - Natal - Rio Grande do Norte
}

Italo Bruno Fonseca de Souza - italoofonsecaa@hotmail.com

Universidade Federal Rural do Semi-Árido

R. Gamaliel Martins Bezerra

59515-000 - Angicos - Rio Grande do Norte

Wendell Rossine Medeiros de Souza - wendell@ufersa.edu.br

Universidade Federal Rural do Semi-Árido

R. Gamaliel Martins Bezerra

59515-000 - Angicos - Rio Grande do Norte

Resumo: Novos desafios de ensino surgem no cenário atual e, principalmente, na educação em disciplinas da área estrutural, normalmente desenvolvidas em contextos práticos. Para atender todos os conteúdos da grade curricular, novas estratégias de ensino são implementadas, como a busca por softwares de fácil manipulação que possibilitem o aprendizado através da simulação do comportamento estrutural das edificações. Desta forma, este artigo apresenta uma proposta de utilização do programa Autodesk ${ }^{\circledR}$ Robot ${ }^{\mathrm{TM}}$ como ferramenta de suporte no ensino remoto da NBR 6123 - Forças devidas ao vento em edificações, norma empregada em projetos estruturais. A metodologia adotada consiste em um estudo comparativo dos resultados das cargas de vento geradas pelo Robot e um exemplo analítico. Os resultados obtidos demonstram a facilidade de uso do programa e como a abordagem pode superar os métodos tradicionais de ensino na disciplina.

Palavras-chave: Análise estrutural. Metodologia de ensino. Autodesk Robot.

\section{INTRODUÇÃO}

O Autodesk ${ }^{\circledR}$ Robot $^{\mathrm{TM}}$ Structural Analysis Professional é um software de análise estrutural incorporado a tecnologia BIM (Modelagem da Informação da Construção), capaz de permitir a integração direta com o Revit (BIANCARDO et al., 2020). O programa é utilizado para auxiliar engenheiros em cálculos estruturais, desde a concepção à simulação de projetos. Para estudantes 
do curso de engenharia civil, sua implementação nas disciplinas pode proporcionar uma experiência diferenciada, principalmente em disciplinas da área de estruturas.

Lana e Machado (2015) ressaltam as vantagens da utilização de softwares livres para ensinar conteúdos complexos através do uso de simulação de modelos reais. Com o atual cenário, vários cursos precisaram se adaptar com a transmissão dos conteúdos de forma remota, fazendo com que essas estratégias, que antes já eram empregadas, tivessem um peso ainda maior na disseminação dos assuntos. O ensino a distância ainda é um desafio para os cursos de engenharia, que normalmente contam com a vivência prática de laboratório e o suporte docente para compreensão das diferentes abordagens matemáticas, necessárias para desenvolvimento dos projetos. No entanto, de acordo com Markova et al. (2017), a principal dificuldade do ensino a distância está na descrença dos alunos que este modelo ofereça contato suficiente com os professores, ou desenvolva a capacidade do aprendizado. Para Novaes (1994), a classificação do ensino a distância está no nível e especialização da instituição.

Diante do exposto, este trabalho tem como objetivo apresentar uma proposta estratégica de ensino trabalhada na Universidade Federal Rural do Semi-Árido (UFERSA) campus Angicos/RN, na disciplina de estruturas do curso de Engenharia Civil, em aulas ministradas a distância. Pela facilidade de manuseio e por ser um software que possui versão estudantil, os discentes conseguiram discutir conceitos importantes relacionados ao dimensionamento das estruturas, tração, compressão e flexão. Para ilustrar o processo de aprendizado será descrito, neste artigo, a simulação de cargas de vento, construída pelos próprios alunos, utilizada para fixação e visualização dos conceitos presentes na NBR 6123 - Forças devidas ao vento em edificações.

\section{REFERENCIAL TEÓRICO}

Diante dos desafios do cenário atual e do crescente número de ofertas dos cursos à distância (EAD), se faz necessário a adoção de metodologias que facilitem a absorção dos conteúdos da grade curricular dos cursos de engenharia. Tal fato se torna mais evidente em disciplinas que necessitam da interação de conteúdos teóricos e práticos. Dessa forma, é necessário oferecer o EAD com a mesma qualidade do ensino presencial (FERNANDES et al., 2019).

\subsection{Autodesk ${ }^{\circledR}$ Robot $^{\mathrm{TM}}$ Structural Analysis Professional}

O Robot é um software de análise estrutural avançada que permite realizar análises lineares e não lineares de modelos de construção, pontes e outros tipos de estruturas industriais, onde pode ser implementado o tipo de material a ser utilizado na concepção estrutural. Duarte (2019) ressalta que este é um software colaborativo e versátil, desenvolvido para o BIM, que fornece ferramentas avançadas de análise e design, o qual permite compreender o comportamento de qualquer tipo de estrutura.

Este programa possui a versão estudantil, o que facilita o acesso para estudantes, podendo ser utilizado por professores como ferramenta de ensino, além de possuir uma interface simples, de fácil manuseio, modelagem e análise de dados. Segundo Piza (2017), o Autodesk Robot Structural Analysis Professional auxilia engenheiros em diversos cálculos estruturais e permite tanto a modelagem 2D como 3D. Além disso, o Robot possui um link que permite a integração com Revit, software também da Autodesk, facilitando o intercâmbio dos dados entre os dois programas. Desse modo, é possível proporcionar transferências e atualizações precisas de modelos, pois possui uma paramétrica gestão de mudanças, que mantém todos os documentos atualizados (PIZA, 2017). 


\subsection{Estudo de forças devido ao vento em edificações}

A NBR 6123 apresenta as considerações, para efeito de cálculo, das forças resultantes da ação estática e dinâmica do vento nas edificações. Segundo a norma, para determinar as forças devido ao vento, os cálculos devem ser realizados separadamente para: elementos de vedação, partes da estrutura (telhados, paredes, etc.) e para a estrutura como um todo. Assim, deve ser considerado as dimensões do edifício, a velocidade básica do vento $\left(\mathrm{V}_{\mathrm{o}}\right)$ e características topográficas (S1, S2) do local, além do fator estatístico (S3) que depende do tipo de edificação.

De acordo com a NBR 6123, as ações de vento são caracterizadas como pressão no edifício quando se obtém valores positivos de carga de vento. Quando esses valores são negativos, significa que as ações são de sucção. Segundo Rios (2015) o comportamento do vento é em geral turbulento, composto de diversos redemoinhos, de diferentes tamanhos e características rotacionais. Estas características fazem com que o vento apresente variações bruscas de velocidade, denominadas rajadas. E o aumento da altura dos edifícios tornam as estruturas cada vez mais suscetíveis às vibrações provocadas pelo vento.

Atualmente, as edificações estão mais esbeltas e problemas dinâmicos causados pelo vento são significativos e muitas vezes, por desconhecimento, os projetistas deixam de fazer verificações importantes, que podem causar desconforto aos usuários ou até mesmo o colapso da estrutura (JUNIOR, 2004). Desse modo, ressalta-se a importância de estudos cada vez mais precisos e simplificados, que forneçam resultados satisfatórios.

\section{METODOLOGIA}

A metodologia utilizada para aplicação das aulas foi dividida em duas atividades: síncrona (Online) e assíncrona (parte em que o aluno desenvolvia em casa). Após a apresentação do conteúdo os alunos desenvolviam o projeto, coletavam os dados no momento assíncrono e debatiam nos encontros online. Os encontros online eram diários para tirar dúvidas, apresentar novos conteúdos, realizar exercícios e para apresentações práticas utilizando o programa. De forma a facilitar o entendimento dos assuntos e apresentar como o Robot foi implementado ao longo da disciplina, a Figura 1 mostra as atividades e abordagens adotadas no ensino a distância. Ressalta-se que toda a disciplina foi desenvolvida em cima da concepção do dimensionamento de um galpão de madeira, projetado e analisado através das simulações obtidas com o programa.

Figura 1 - Atividades realizadas dentro da disciplina.

\begin{tabular}{|c|c|c|}
\hline $\begin{array}{l}\text { Lançamento de estruturas } \\
\text { (Revit e Robot) }\end{array}$ & $\begin{array}{l}\text { Cálculo de cargas } \\
\text { (Revit e Robot) }\end{array}$ & $\begin{array}{c}\text { Lançamento das cargas } \\
\text { (Robot) }\end{array}$ \\
\hline $\begin{array}{l}\text { 1. Elaboração do projeto, descrição } \\
\text { dos elementos estruturais. }\end{array}$ & $\begin{array}{l}\text { 1. Elaborado o projeto no Revit foi } \\
\text { tirado o volume do madeiramento } \\
\text { (caibros de ripas). } \\
\text { 2. Já no Robot foi calculado as } \\
\text { ações do vento na estrutura. }\end{array}$ & $\begin{array}{l}\text { 1. Aplicação de carga de acordo } \\
\text { com sua natureza (permanente, } \\
\text { Acidental, etc). }\end{array}$ \\
\hline $\begin{array}{c}\text { Combinações dos esforços } \\
\text { (Robot) }\end{array}$ & $\begin{array}{c}\text { Análise estrutural } \\
\text { (Robot })\end{array}$ & $\begin{array}{c}\text { Dimensionamento } \\
\text { (Excel) }\end{array}$ \\
\hline $\begin{array}{l}\text { 1. Considerando o que preconiza a } \\
\text { NBR } 7190 \text { foram implementados } \\
\text { no programa as possíveis } \\
\text { combinações dos esforços. }\end{array}$ & $\begin{array}{l}\text { 1. Análise dos esforços na estrutura } \\
\text { (compressão, tração, flexão). }\end{array}$ & $\begin{array}{l}\text { 1. Com os dados dos esforços, foi } \\
\text { elaborada uma planilha que } \\
\text { calculava as peças. }\end{array}$ \\
\hline
\end{tabular}


(C) COBENCE

"Os desafios para formar hoje o engenheiro do amanhã"

Fonte: O autor (2020).

Como é mostrado na Figura 1, as atividades iniciaram-se a partir da modelagem computacional no Revit e Robot, descrevendo os materiais e elementos estruturais. Em seguida, após a elaboração do projeto no Revit, foi extraído as informações de volume para cálculo das cargas do madeiramento (Caibros e ripas). Já no Robot foi calculado as ações do vento na estrutura e em seguida lançado as cargas. De acordo com NBR 7190, para dimensionamento de estruturas de madeiras, a combinação de esforços foi realizada dentro da própria interface do programa.

Após a geração dessas combinações, as ações nas estruturas foram calculadas e os esforços resultantes (compressão, tração, flexão) analisados. A partir desses dados, foram elaboradas planilhas que permitiram o dimensionamento das peças. Além disso, como meio de ensino remoto da NBR 6123 foi realizado um comparativo de resultados das cargas de vento, utilizando um exemplo de Pinheiro (2005), presente na Figura 2, com o projeto de um galpão, com cargas de vento simuladas no Robot. Para realizar a simulação de vento no programa, a estrutura do galpão foi modelada seguindo as mesmas dimensões e inclinações fornecidas no exemplo. O galpão possui uma largura de $20 \mathrm{~m}$ e comprimento de $30 \mathrm{~m}$, com pé direito de $5 \mathrm{~m}$ e telhado com 2 águas de inclinação de $15^{\circ}=27 \%$, como é mostrado na Figura 2.

Figura 2 - Dimensões do galpão do exemplo.

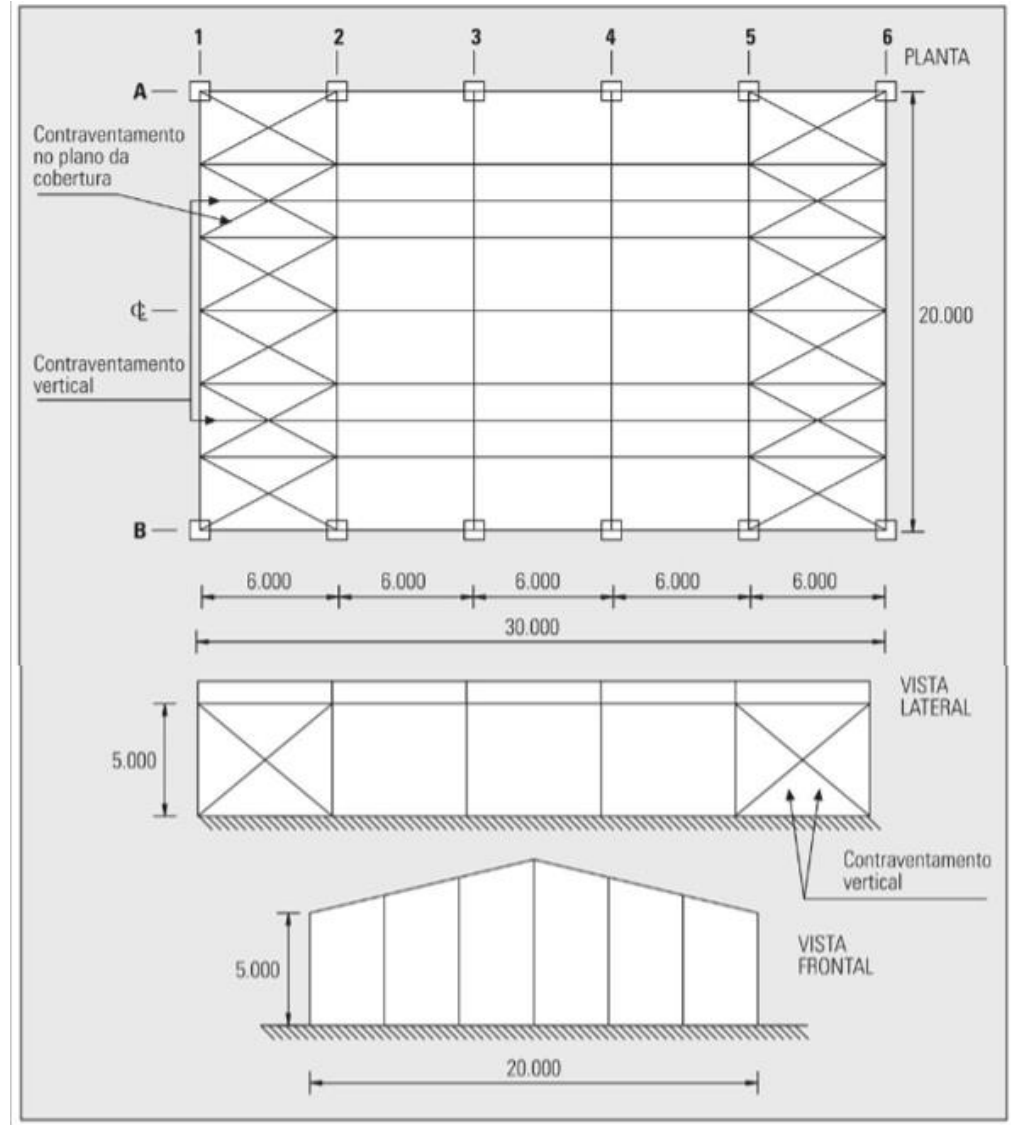

Fonte: Pinheiro (2005). 


\section{Evento On-line}

\section{ANÁLISE DOS DADOS E RESULTADOS}

No exemplo analítico utilizado, seguindo a NBR 6123, Pinheiro (2005) obteve os resultados apresentados na Figura 3, com as combinações dos coeficientes de pressão a $0^{\circ}$ e $90^{\circ}$, das paredes e telhado.

Figura 3 - Coeficientes de pressão $0^{\circ}$ e $90^{\circ}$.

A) $C_{e}\left(\alpha=90^{\circ}\right)+C_{i}(+0,2)$ (Fig. 11.12)

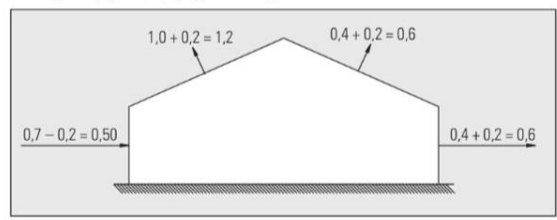

B) $C_{e}\left(\alpha=90^{\circ}\right)+C_{i}(-0,3)$ (Fig. 11.13)

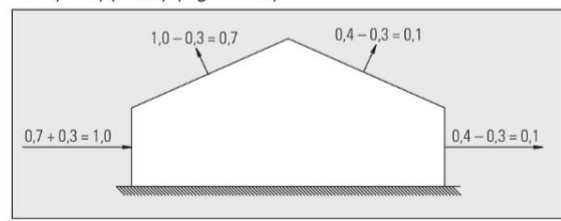

C) $C_{e}\left(\alpha=0^{\circ}\right)+C_{i}(+0,2)$ (Fig. 11.14)

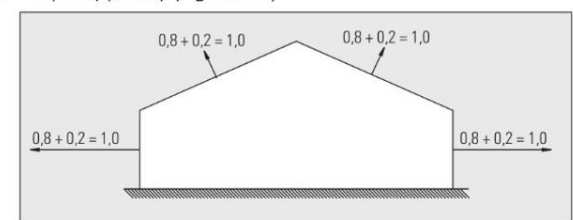

D) $C_{e}\left(\alpha=0^{\circ}\right)+C_{i}(-0,3)$ (Fig. 11.15)

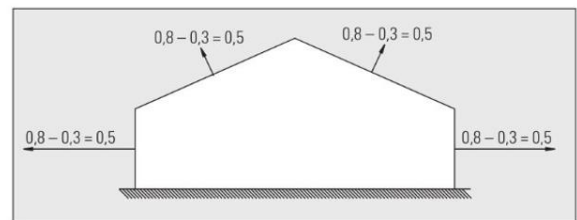

Fonte: Pinheiro (2005).

Para cálculo das ações devido o vento, Pinheiro (2005) considerou as combinações A e B, o que resultou nas cargas da Figura 4.

Figura 4 - Cargas resultantes das combinações.

CASO A

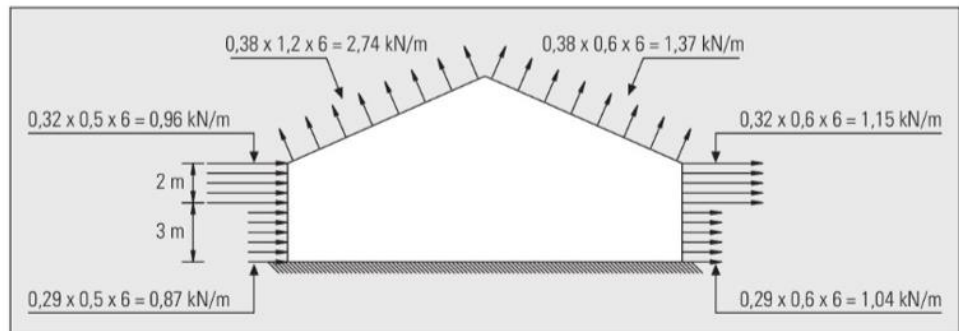

CASO B

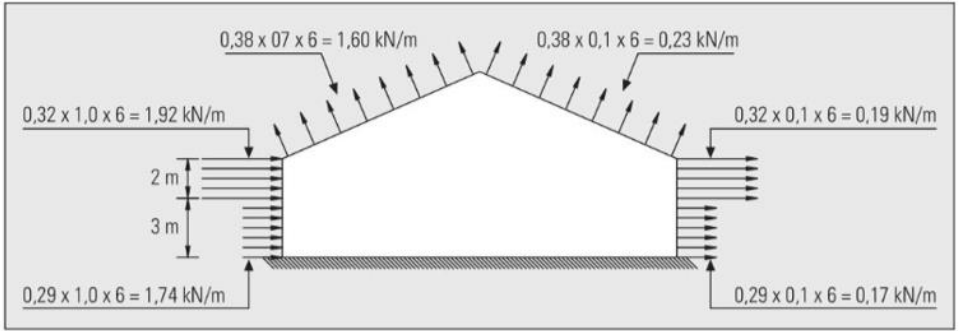

Fonte: Pinheiro (2005). 
Nos dois casos resultados da análise do autor, é notório que a fachada do lado esquerdo, no vento à $90^{\circ}$, está submetida a ações de pressão. Quanto a fachada do lado direito e a cobertura estão submetidas a ações de sucção. A norma ainda ressalta, que existe uma zona da cobertura que estará sujeira a uma pressão de sucção maior, por isso muitas vezes ocorre o deslocamento de telhas da cobertura. Dessa forma, é necessário conhecer as pressões que ocorrem nessa área. Essa área pode ser compreendida a partir da identificação da região hachurada na Figura 5.

Figura 5 - Pressões em áreas específicas na cobertura.

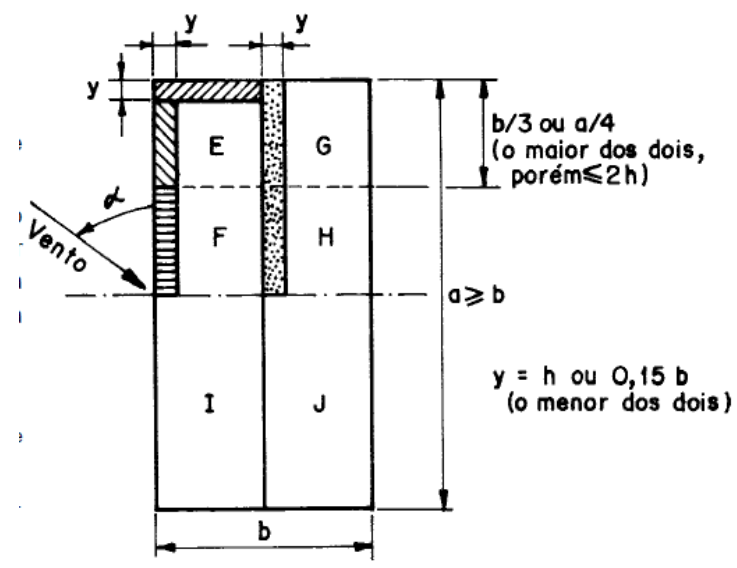

Fonte: NBR 6123 (1988).

Desse modo, espera-se que a simulação de vento feita no programa, forneça resultados semelhantes com as ações de pressão e sucção, ocorrendo como nos resultados do exemplo. No Robot, a estrutura do galpão elaborada pelos alunos, obteve as características da Figura 6.

Figura 6 - Modelagem do galpão.

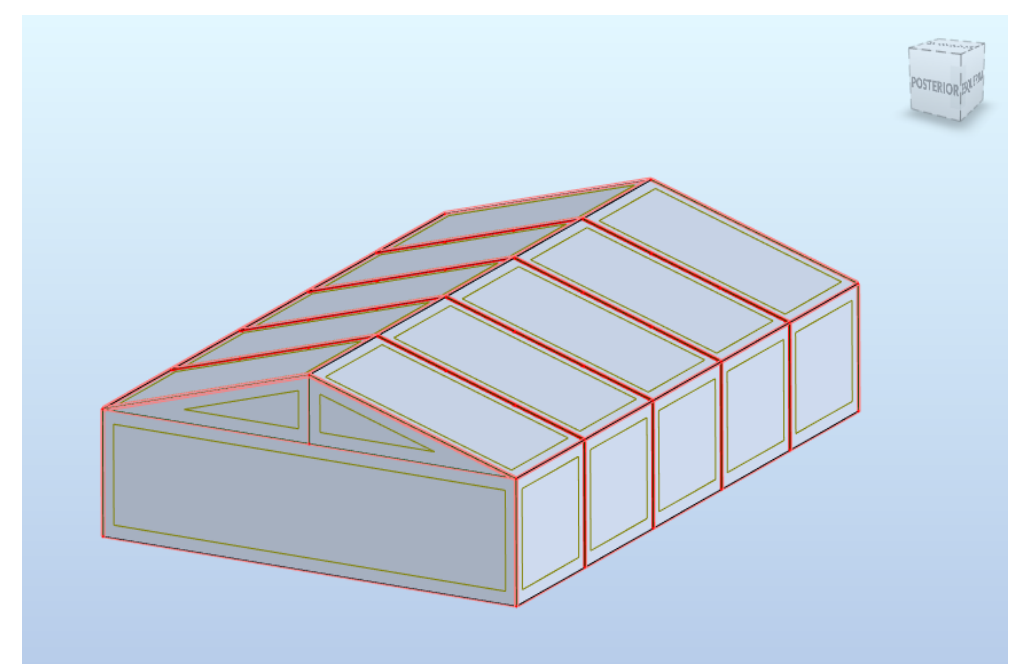

Fonte: O autor (2020). 
Após a elaboração da estrutura, iniciou-se a simulação do vento a $0^{\circ}$ e $90^{\circ}$, e foram obtidos os seguintes resultados, para as pressões nas duas direções: $0^{\circ}$ e $90^{\circ}$ (Figura 7).

Figura 7 - Simulação do vento a 7.1 - $0^{\circ}$ e 7.2 - $90^{\circ}$.

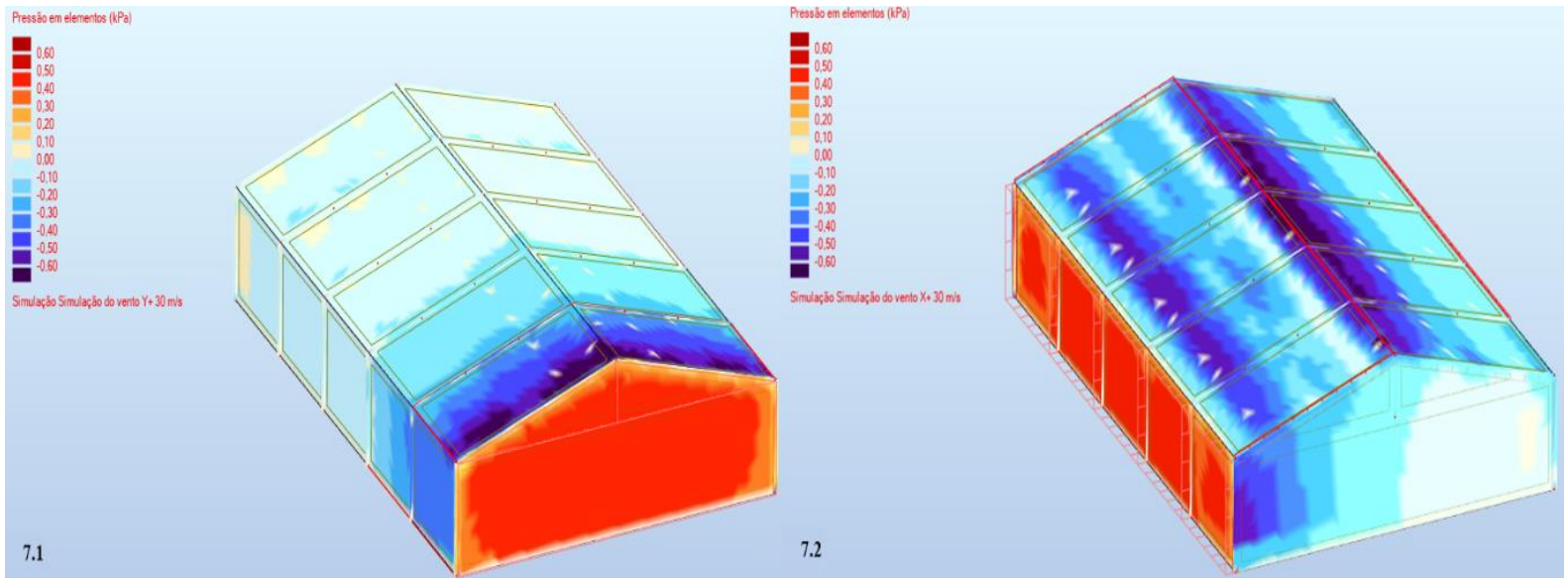

Fonte: O autor (2020).

A partir da escala de cores ao lado das imagens, os alunos foram capazes de observar a variação das pressões por meio das cores. Regiões com coloração variando de vermelho escuro a um amarelo claro, estão sob ação de cargas de pressão. Enquanto as regiões com coloração de azul piscina a violeta estão sob sucção. Analisando as imagens é possível observar que as colorações indicam resultados satisfatórios e coerentes com a norma. Onde na simulação a $0^{\circ}$ (Figura 7.1), as ações do vento possuem valores de pressões maiores na face que "recebe" ação do vento e reduz ao longo do comprimento do edifício. Outro ponto importante a ser observado, ainda na Figura 7.1 da simulação a $0^{\circ}$, é a zona com coloração azul escuro (azul marinho), que indica uma região que está sob ação de sucção na cobertura, ou seja, com uma pressão saindo do telhado, estando de acordo com a área hachurada e mencionada anteriormente.

Na Figura 7.2 da simulação a $90^{\circ}$ e no resultado das pressões a $90^{\circ}$ do exemplo utilizado por Pinheiro (2005), é possível notar a semelhança entre o sentido das ações resultantes da análise do autor e a coloração das regiões da imagem, indicando as áreas que estão sob sucção ou pressão. As mesmas regiões que foram classificadas com pressão e sucção no exemplo, obtiveram colorações similares no programa, onde na face esquerda do galpão, o mesmo está sob ações de pressões que diminuem ao longo da largura do galpão.

Olhando para a cobertura, é possível notar que a cumeeira e a região próxima ao beiral esquerdo, possuem cor azul mais escura, indicando uma região sob sucção mais significativa (Figura 8). Observa-se que a face oposta à que recebe o vento, que apresenta uma cor azul clara, entende-se como sendo uma região com valores menores de sucção, já que a pressão reduz ao longo da largura do galpão. 
Figura 8 - Simulação vendo a $90^{\circ}$.

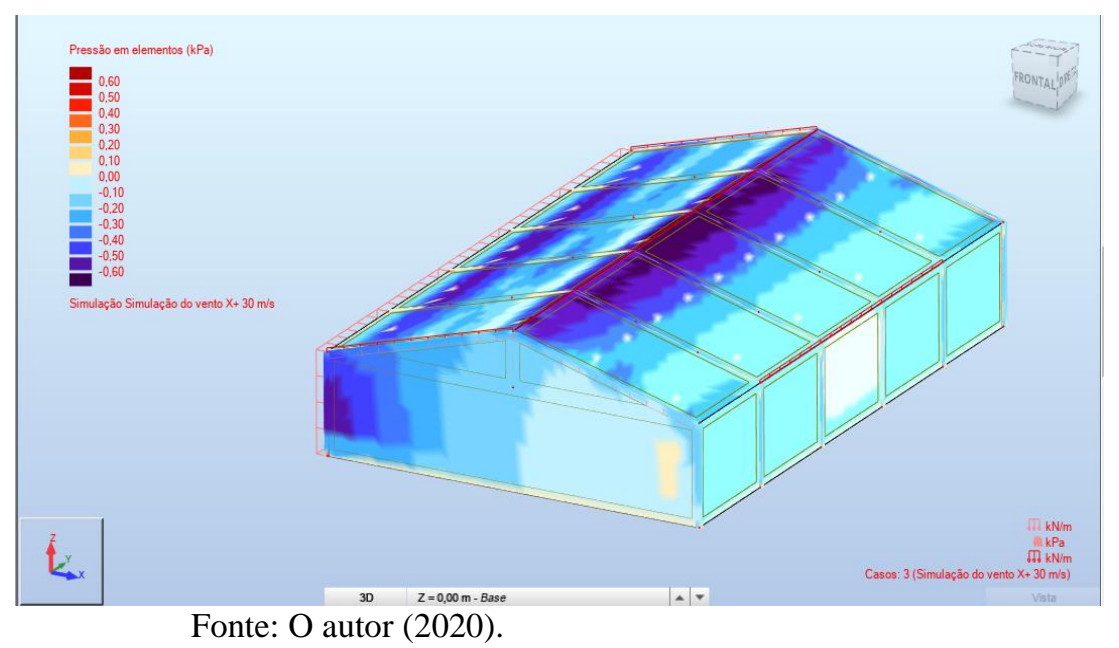

$\mathrm{Na}$ fachada do lado esquerdo do galpão, na simulação a $90^{\circ}$ (Figura 7.2), a região de cor laranja tem uma carga distribuída por $\mathrm{m}^{2} \mathrm{de} 0,43 \mathrm{KN} / \mathrm{m}^{2}$. Sendo a distância entre as tesouras de $6 \mathrm{~m}$, temos uma carga linear de $2,58 \mathrm{KN} / \mathrm{m}$, nesta face e na face oposta (azul claro) de 0,66 $\mathrm{KN} / \mathrm{m}$. Considerando a carga por $\mathrm{m}^{2}$ na cobertura de $0,31 \mathrm{KN} / \mathrm{m}^{2}$ e $0,32 \mathrm{KN} / \mathrm{m}^{2}$ para o lado esquerdo e direito, temos uma carga linear de $1,86 \mathrm{KN} / \mathrm{m}$ e $1,92 \mathrm{KN} / \mathrm{m}$, respectivamente. Estas considerações estão apresentadas na Figura 9, de forma a facilitar a visualização dos alunos quanto a simulação construída.

Figura 9 - As cargas de vento resultantes da simulação no Robot.

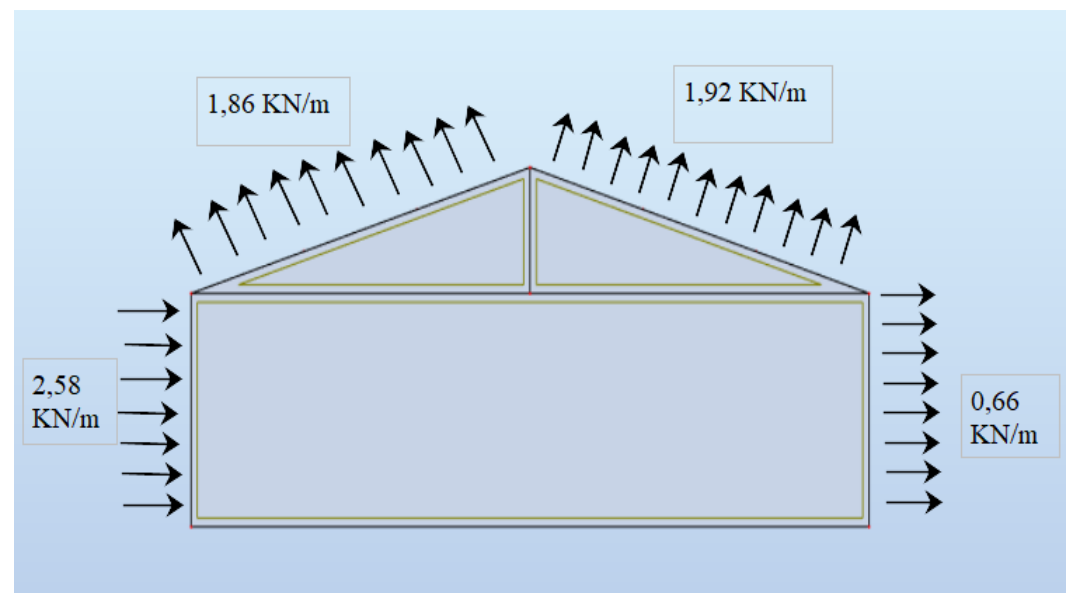

Fonte: O autor (2020).

A diferença de valores resultantes do exemplo e no Robot, pode ser justificada pela diferença em alguns coeficientes da norma americana e a brasileira, já que o Robot não possui critérios da norma brasileira e sua base de cálculo é feita a partir da norma americana. Diante do comparativo entre o exemplo e a utilização do programa para validação dos critérios da norma, foi possível notar uma melhor compreensão e aprendizagem do conteúdo utilizando o programa como ferramenta de auxílio na disciplina. Além de proporcionar aos discentes trabalhar com a comparação entre teoria e prática, também possibilitou o conhecimento de uma nova ferramenta de análise. 


\section{CONSIDERAÇÕES FINAIS}

Após a comparação entre os resultados obtidos com o software Robot, por meio do exemplo apresentado, é possível notar que a utilização deste tipo de metodologia ajuda a suprir o medo do aprendizado à distância levantado por Markova et al. (2017). Em resposta às aulas, os alunos argumentaram maior facilidade em compreender o conteúdo e demonstraram satisfação com a possibilidade de utilizar o software futuramente em ambiente profissional. Além disso, foi possível visualizar o exemplo prático 2D apresentado no livro sendo representado em 3D no programa, por meio de toda a representação das ações no galpão. Desta forma, constata-se que o programa se mostrou de fácil acesso e manuseio, sendo uma boa ferramenta de aprendizagem, superando didáticas de ensino tradicionais.

Como sugestão para trabalhos futuros, pode-se ressaltar a utilização do programa para realização de projetos utilizando outros materiais, como o aço ou concreto, fazendo todas as adaptações para atender a norma vigente.

\section{Agradecimentos}

Gostaríamos de agradecer a Universidade Federal Rural do Semi-Árido e a Autodesk por disponibilizar o programa na versão estudantil, permitindo assim o desenvolvimento dessa proposta.

\section{REFERÊNCIAS}

ASSOCIAÇÃO BRASILEIRA DE NORMAS TÉCNICAS. NBR 6123: Forças devidas ao vento em edificações. Rio de Janeiro, 1988. 66 p.

BIANCARDO, S. A. et al. BIM Approach for Modeling Airports Terminal Expansion. Infrastructures, [s.1.], v. 5, n. 41, p. 1-14, 2020.

DUARTE, Débora Sofia Silva. Projeto de Estruturas de um Hotel no Porto. 2019. 239 f. Tese (Mestrado) - Instituto Superior de Engenharia do Porto, Porto, 2019.

FERNANDES, S. M.; HENN, L. G.; KIST, L. B. O Ensino a distância no Brasil: Alguns apontamentos. Revista Research, society and development, v.9, n.8, 2019.

JUNIOR, Célio Fontão Carril Ação do vento nas estruturas. $3^{\circ}$ Congresso Temático de Dinâmica e Controle da SBMAC, 2004. UNESP - Campus de Ilha Solteira. Anais. São Paulo, 2004.

LANA, Elinor F. D.; Machado, NIELSEN L. R. A importância da utilização de softwares para a melhoria da metodologia de ensino. In: VI Seminário Nacional de Formação de Professores/UFSM, 2015, Rio Grande do Sul. Anais. Santa Maria, 2015.

MARKOVA, T; GLAZKOVA, I.; ZABOROVA, E. Quality Issues of Online Distance Learning. Procedia - Social and Behavioral Sciences, [s.1.], v. 237, p. 685-691, 2017.

NOVAES, A. G. Ensino à distância na engenharia: Contornos e perspectivas. Gestão \& Produção, [s.1.], v. 1, n. 3, p. 250-271, 1994.

PINHEIRO, Antonio Carlos da Fonseca Bragança (ed.). Estruturas Metálicas: cálculos, detalhes, exercícios e projetos. $2^{a}$ edição, São Paulo: Edgard Blucher, 2005. 317 f. 
PIZA, Isabella Faria. Roteiro de modelagem estrutural utilizando a tecnologia Bim, desde a modelagem no Revit até a Análise Estrutural no Robot. 2017. 84 f. Monografía (Graduação) - Universidade Tecnológica Federal do Paraná - UTFPR, Campo Mourão, 2017.

RIOS, Marina Polónia. Efeito de amortecedores no comportamento dinâmico de edifícios altos sob cargas de vento. 2015. 136 f. Dissertação (Mestrado) - Pontifícia Universidade Católica do Rio de Janeiro, Rio de Janeiro, 2015.

\title{
USE OF A STRUCTURAL ANALYSIS PROGRAM AS A DISTANCE EDUCATION STRATEGY IN ENGINEERING: A STUDY ON WIND LOADS GENERATED BY AUTOMATIC SIMULATION
}

\begin{abstract}
New teaching challenges arise in the current scenario and mainly in engineering education, in disciplines in the structural area, which are developed in a more practical context. To meet all the contents of the curriculum in the area of structures, new teaching strategies are implemented, such as the search for easy-to-use software that enables learning through the simulation of the structural behavior of buildings. Thus, this article presents a proposal to use the Robot program as a support tool in the remote teaching of NBR 6123 - Forces due to wind in buildings, a standard used in structural projects. The adopted methodology consists of a comparative study of the results of the wind loads generated by the Robot and an analytical example according to NBR 6123. The results obtained demonstrate the ease of use of the program and how the approach can overcome the traditional teaching methods in the discipline.
\end{abstract}

Keywords: Structural analysis, Teaching methodology, Autodesk Robot. 